\title{
Management of pulmonary aspergilloma in the presence of active tuberculosis
}

\author{
ADEBAYO O ADEYEMO, EZEKIEL O ODELOWO, DOROTHY I MAKANJUOLA \\ From the Departments of Surgery and Radiology, Faculty of Health Sciences, University of Ife, and the Chest \\ Clinic, Ife University Teaching Hospitals Complex, Ile-Ife, Nigeria
}

\begin{abstract}
Eleven cases of pulmonary aspergilloma complicating active cavitating pulmonary tuberculosis are reviewed. Nine of the 10 patients who had combined medical (antituberculosis drugs) and surgical treatment were cured of their disease; one patient, who had bilateral multiple aspergillomas, died from massive haemoptysis after resection of one of the affected lobes. The only medically treated patient who refused surgery had fatal haemoptysis at home. Pulmonary resection is recommended for patients who are fit for operation whenever the diagnosis of aspergilloma is made because most published reports indicate that only a few patients benefit from drug treatment alone.
\end{abstract}

The natural history of intracavitary aspergilloma, which is caused by the ubiquitous fungus Aspergillus fumigatus, remains unknown. Many reports, however, indicate that this opportunistic fungus colonises cavities in the upper lobes that result from pulmonary tuberculosis, lung cyst, lung abscess, bronchiectasis, neoplasms, ${ }^{1-3}$ sarcoidosis, and ankylosing spondylitis. ${ }^{45}$ The saprophyte forms a conglomeration of fragmented hyphae, fibrin, and inflammatory cells (called an aspergilloma, fungus ball, or mycetoma) with the radiological appearance of a crescent of air separating the mycetoma from the wall of the cavity. ${ }^{16-8}$ Patients who have old tuberculous cavities with superimposed aspergillomas tend to have recurrent and life threatening haemoptysis, ${ }^{5-14}$ and this is clearly an important factor to be considered in assessing their need for surgery. Consequently, this study was undertaken to review our experience of the incidence, natural history, diagnosis, and management of pulmonary aspergilloma seen in residual tuberculous cavities in a chest clinic serving a rural and urban population where pulmonary tuberculosis is endemic. This represents the largest published series from a single institution in our geographical zone.

Address for reprint requests: Dr Adebayo O Adeyemo, Department of Surgery, Faculty of Health Sciences, University of Ife, Ile-Ife, Nigeria.

Accepted 1 June 1984

\section{Patients}

Of 1345 patients with pulmonary tuberculosis seen in the chest clinic of the University of Ife Teaching Hospital, Ile-Ife, Nigeria, from January 1977 to September 1983, 11 were admitted with pulmonary aspergilloma (table 1). Ages ranged from 29 years to 61 years. There were seven men and four women. The chest radiograph was available for review in all cases and figures 1-5 are representative of the group.

\section{Clinical manifestations}

Table 2 summarises the important clinical features in the 11 patients with aspergilloma associated with pulmonary tuberculosis. The duration of illness until presentation at the hospital ranged from one week to one and half years and the most frequent complaint was of recurrent haemoptysis, usually of one to two days duration. Fever, productive cough, weight loss, and repeated haemoptysis with varying degrees of anaemia occurred in all patients. Five of the patients with severe or advanced pulmonary tuberculosis presented with dyspnoea and fatigue. There were four cases of finger clubbing.

\section{Diagnosis}

Acid fast bacilli were present in the sputum smear of nine of the 11 patients and the remaining two had 
Management of pulmonary aspergilloma in the presence of active tuberculosis

Table 1 Clinical summary and management of 11 patients with pulmonary aspergilloma in the presence of active tuberculosis

\begin{tabular}{|c|c|c|c|c|c|c|c|}
\hline \multirow{2}{*}{$\begin{array}{l}\text { Patient } \\
\text { No }\end{array}$} & \multirow{2}{*}{$\begin{array}{l}\text { Age (y) } \\
\text { and Sex }\end{array}$} & \multirow{2}{*}{$\begin{array}{l}\text { Location of } \\
\text { fungus ball }\end{array}$} & \multicolumn{2}{|c|}{ Sputum } & \multirow[t]{2}{*}{ Management } & \multirow[t]{2}{*}{ Complications } & \multirow[t]{2}{*}{ Outcome } \\
\hline & & & $\boldsymbol{A F B}$ & Fungus & & & \\
\hline 1 & $35 \mathrm{~F}$ & Right upper lobe & & + & $\begin{array}{l}\text { Streptomycin, aminosalocylic acid, isoniazid; } \\
\text { lobectomy }\end{array}$ & Atelectasis & Recovery \\
\hline 2 & $55 \mathrm{M}$ & Left upper lobe & + & & $\begin{array}{l}\text { Streptomycin, aminosalicylic acid isoniazid, } \\
\text { clindamycin; lobectomy }\end{array}$ & Empyema thoracis & Recovery \\
\hline 3 & $49 \mathrm{M}$ & Left upper lobe & + & & $\begin{array}{l}\text { Streptomycin, aminosalicylic acid isoniazid, } \\
\text { ampicillin; lobectomy }\end{array}$ & Wound infection & Recovery \\
\hline 4 & $46 \mathrm{~F}$ & Left upper lobe & + & + & $\begin{array}{l}\text { Streptomycin, ethambutol, isoniazid; refused } \\
\text { surgery }\end{array}$ & $\begin{array}{c}\text { Exsanguinating } \\
\text { haemoptysis }\end{array}$ & Died \\
\hline 5 & $49 \mathrm{~F}$ & $\begin{array}{l}\text { Left upper lobe } \\
\text { (fig 2) }\end{array}$ & & + & $\begin{array}{l}\text { Streptomycin, ethambutol, isoniazid, ampicillin, } \\
\text { clindamycin; left pneumonectomy }\end{array}$ & Empyema thoracis & Recovery \\
\hline 6 & $50 \mathrm{M}$ & Right upper lobe & + & & Streptomycin, ethambutol, isoniazid; lobectomy & $\begin{array}{l}\text { Wound infection, } \\
\text { empyema thoracis }\end{array}$ & Recovery \\
\hline 7 & $29 \mathrm{M}$ & Left upper lobe & + & & Streptomycin, rifampicin, isoniazid; lobectomy & & $\begin{array}{l}\text { Uneventful } \\
\text { recovery }\end{array}$ \\
\hline 8 & $47 \mathrm{~F}$ & $\begin{array}{l}\text { Right and left } \\
\text { upper lobe } \\
\text { (figs } 3 \text { and 4) }\end{array}$ & + & + & $\begin{array}{l}\text { Streptomycin, rifampicin, isoniazid; left upper } \\
\text { lobectomy (1st stage) }\end{array}$ & $\begin{array}{l}\text { Massive haemoptysis on } \\
\text { 6th postoperative } \\
\text { day }\end{array}$ & Died \\
\hline 9 & $32 \mathrm{M}$ & Right upper lobe & + & & Streptomycin, aminosalicylic acid; lobectomy & & $\begin{array}{l}\text { Uneventful } \\
\text { recovery }\end{array}$ \\
\hline 10 & $38 \mathrm{M}$ & Left upper lobe & + & & $\begin{array}{l}\text { Streptomycin, aminosalicylic acid, isoniazid; } \\
\text { lobectomy }\end{array}$ & & $\begin{array}{l}\text { Uneventful } \\
\text { recovery }\end{array}$ \\
\hline 11 & $34 \mathrm{M}$ & $\begin{array}{l}\text { Left upper lobe } \\
\text { (fig 5) }\end{array}$ & + & & Streptomycin, rifampicin, isoniazid; lobectomy & & $\begin{array}{l}\text { Uneventful } \\
\text { recovery }\end{array}$ \\
\hline
\end{tabular}

AFB—acid fast bacilli.

Table 2 Clinical features of 11 patients with pulmonary aspergilloma in the presence of active tuberculosis

\begin{tabular}{lc}
\hline Presenting manifestations & No of cases \\
\hline Increased productive cough & 11 \\
Recurrent haemoptysis & 11 \\
Weight loss & 9 \\
Excessive night sweat & 8 \\
Dyspnoea & 5 \\
Fatigue & 5 \\
Finger clubbing & 4 \\
\hline
\end{tabular}

acid fast bacilli cultured from the sputum; A fumigatus was recovered from the sputum in four cases. Histological examination of resected surgical specimens confirmed the diagnosis of pulmonary tuberculosis and aspergilloma in all 11 cases. The skin patch test and serum precipitin (gel diffusion) test were not done because of lack of facilities.

Standard posteroanterior chest views were performed in all cases. Lateral views and tomography were obtained when necessary. The hallmark of the radiological diagnosis of pulmonary aspergilloma is the presence of a moon shaped radiolucency adjacent to a rounded mass within a cavitary lesion on the chest radiograph, and the fungus ball (aspergilloma) often alters its location as the patient changes position. In three cases the aspergilloma appeared as a smooth homogenous, rather circular mass occupying a small fraction, usually the base, of a thin walled cavity (fig 1). In seven cases the aspergillomas occupied virtually the entire cavity (fig 2 ). In one treated tuberculous patient, bilateral aspergillomas appeared in previous empty bilateral thin walled cavities, as shown by chest radiographs (figs 3 and 4) taken in 1974 and 1980 . The aspergillomas were all located in the upper lobe except in the patient with bilateral aspergillomas, one of which was located in the right middle lobe; eight occurred on the left side and four on the right.

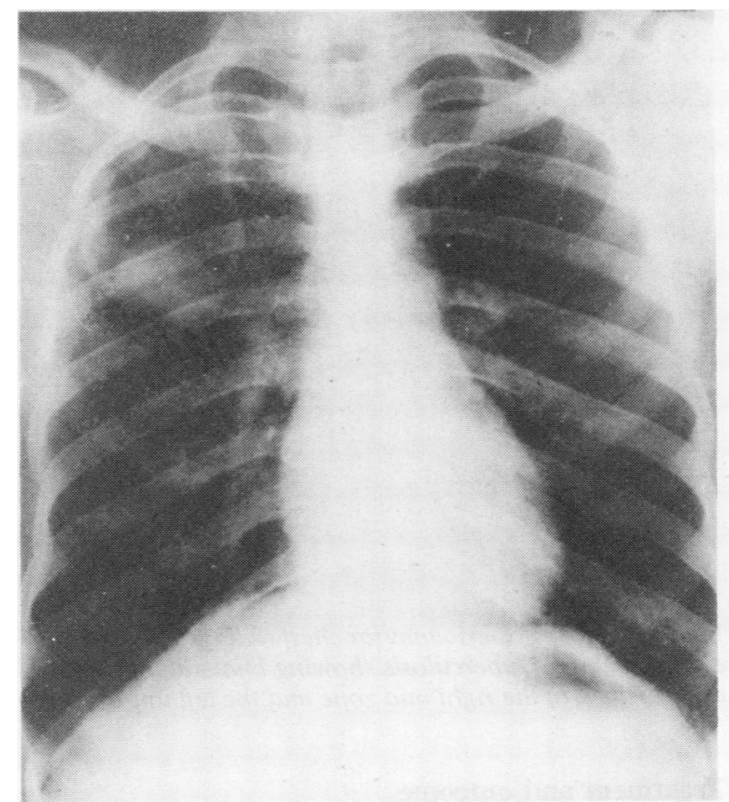

Fig 1 Case 1: Posteroanterior chest radiograph of a treated tuberculous patient showing a fungus ball located at the base of a thin walled cavity in the right upper lobe. 


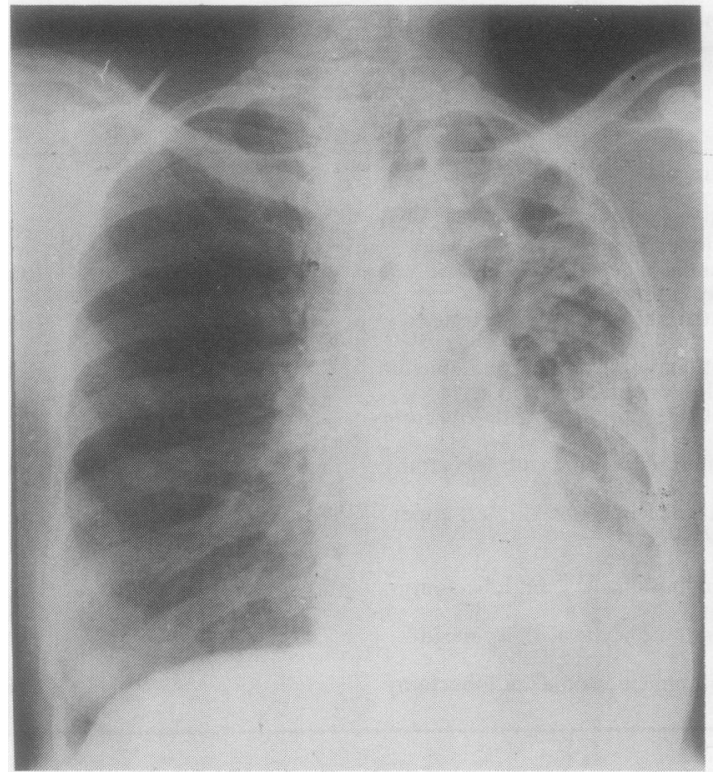

Fig 2 Case 5: Posteroanterior chest radiograph of a chronic tuberculous patient showing a fungus ball occupying the entire left upper lobe. The left lower lobe is the seat of chronic tuberculous changes.

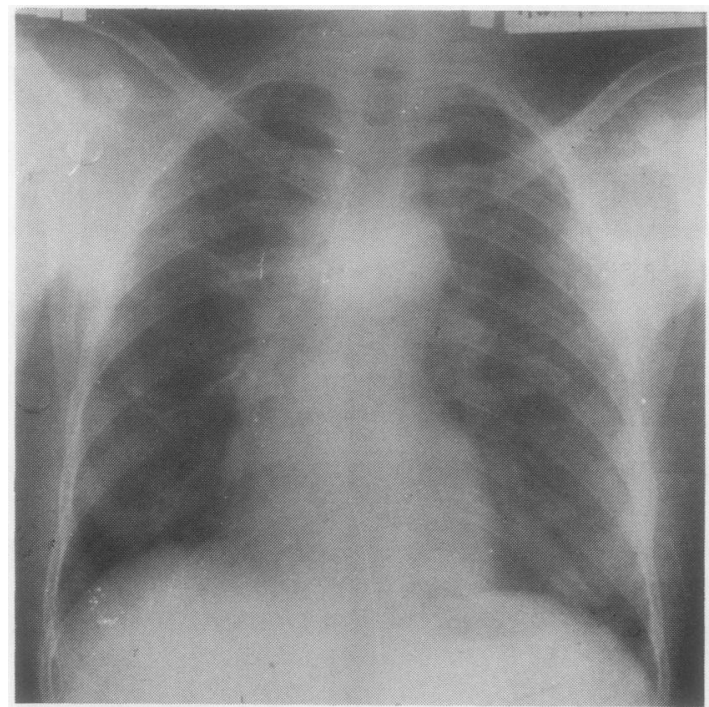

Fig 3 Case 8: Posterioanterior chest radiograph (1974) of a treated case of tuberculosis showing bilateral thin walled cysts located in the right mid zone and the left upper zone.

\section{Treatment and outcome}

Table 1 shows the mode of treatment and its outcome in each case. The mainstay of treatment is a

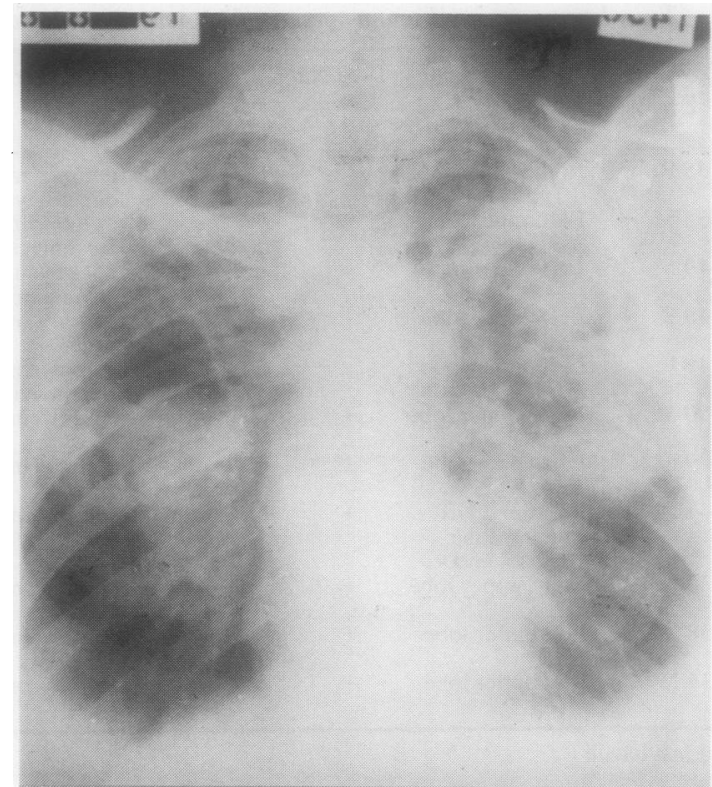

Fig 4 Case 8: Posteroanterior radiograph of the same patient, taken six years later (1980). Fungal balls have appeared in both cavities. The lung fields also show many infiltrates.

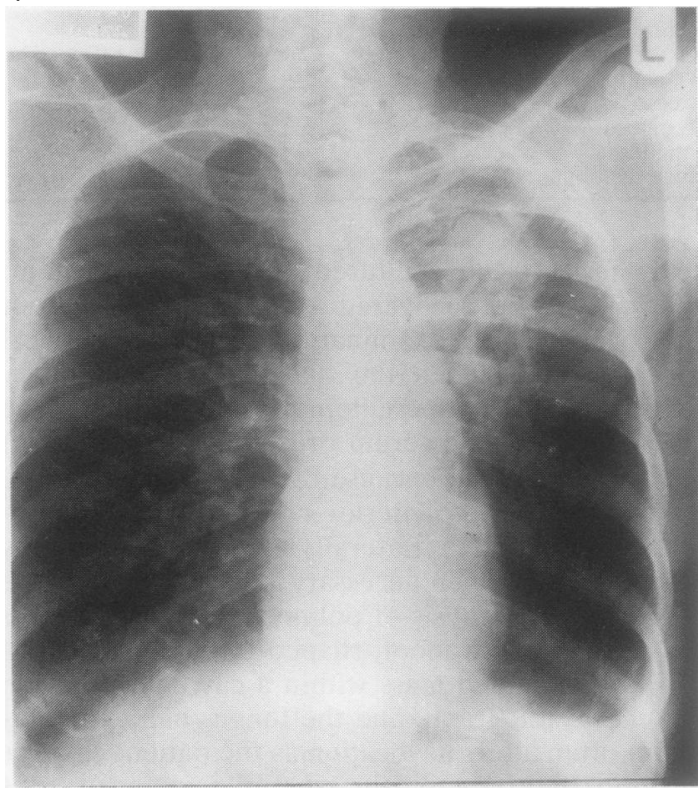

Fig 5 Case 11: Posteroanterior chest radiograph of a tuberculous patient showing a fungus ball in the left upper lobe.

combined medical and surgical approach. The medical treatment consisted of antituberculous chemotherapy, consisting of daily intramuscular injections 
of streptomycin for three months and oral administration of a combination of isoniazid with either aminosalicylic acid or ethambutol or rifampicin for 18 to 24 months. Supportive blood transfusion was given to those who had a packed cell volume below $0 \cdot 25$. The surgical treatment consisted of either lobectomy (nine patients) or pneumonectomy (one patient) whenever the patient was physically fit for anaesthesia, since nearly all the lobes habouring the aspergilloma had been destroyed by the concurrent tuberculosis. One patient had left pneumonectomy (fig 2) because the left lung was completely fibrosed and studded with tubercles. The only patient with bilateral aspergillomas (fig 4) was scheduled to have staged resection but had only left upper lobectomy when she had a fatal haemoptysis on the sixth postoperative day. The eleventh patient, who refused to have surgery despite recurrent haemoptysis, eventually died at home after a massive haemoptysis. The postoperative complications included wound infection and empyema thoracis, which were treated effectively by the administration of appropriate antibiotics. Intrapleural instillation of antibiotics to which the organisms were sensitive combined with tidal irrigation of the infected pleural cavity with normal saline solution helped in reducing the postoperative morbidity.

\section{Discussion}

Aspergillus fumigatus is the most common cause of human aspergillosis and pulmonary aspergilloma. ${ }^{14} 7$ The natural history of intracavitary aspergilloma is not well documented but the published data indicate that intracavitary aspergilloma results from saprophytic colonisation of areas of lung tissue that have been destroyed by sarcoidosis, ${ }^{4}$ tuberculosis, bronchiectasis, lung abscesses, and neoplasms. ${ }^{13}$ Israel and Ostrow ${ }^{4}$ in 1969 documented the association of sarcoidosis and aspergilloma in the chronic cystic cavities of upper lobes in patients with pulmonary sarcoidosis. Despite the frequent occurrence of pulmonary sarcoidosis in black Americans, it is not a common pulmonary disease in our environment.

The establishment of a definitive diagnosis of aspergillosis, from either sputum or tissue culture is often fraught with difficulty because airborne Aspergilli spores, being ubiquitous, commonly produce laboratory contamination and the role of A fumigatus as a pathogen is often overlooked. ${ }^{17-19}$ The fungus was recovered from the sputum in only four of our 11 cases. This low recovery rate is likely to be due to the mycetoma's intracavitary location and its non-communication with the bronchus, as previously suggested..$^{16717}$ The sputum tests were positive for Mycobacterium tuberculosis from a smear in nine cases and from culture in two cases. This high incidence of positivity for acid fast bacilli was due to the fact that all patients still had active tuberculosis disease.

Most lesions are unilateral but isolated instances of multiple bilateral aspergillomas have been recorded. ${ }^{81121}$ Our case of a 47 year old woman (No 8 in table 1) complements the list of the few reported cases of bilateral pulmonary aspergilloma in English publications.

The mainstay of treatment in all our cases consisted of combined preoperative and postoperative antituberculosis treatment, correction of anaemia, and subsequent surgical resection of the lobe housing the aspergilloma, provided that the pulmonary state and the clinical condition of the patient did not preclude surgery. Lobectomy or pneumonectomy was preferred to segmental resection, in the hope of forestalling pleural contamination with aspergilli that could lead to recurrent fungal infection in the form of empyema and bronchopleurocutaneous fistula, which may be refactory to all forms of treatment. ${ }^{2}$ We share the view of others that surgical resection of the affected lobe is the treatment of choice for aspergilloma coexisting with pulmonary tuberculosis, ${ }^{2111522}$ particularly because of the high incidence of exsanguinating haemoptysis in untreated cases.

Henderson and Pearson ${ }^{23}$ treated three cases of pulmonary aspergilloma by local surgical evacuation of the cavity followed by irrigation of the cavity with natamycin. These patients, however, had had prior treatment with intrabronchial instillations of natamycin without any benefit. Amphotericin B is still acclaimed as the most effective antifungal antibiotic available for invasive aspergillosis ${ }^{24}$ but its effect on pulmonary aspergilloma is still in doubt. A few reports indicate that cure of aspergilloma with various antifungal drugs given orally, parenterally, ${ }^{3}$ endobronchially, ${ }^{25}$ or by repeated intracavitary instillations of brilliant green ${ }^{5}$ or a paste containing nystatin or amphotericin $B^{26}$ is possible, though many reports 81114152022 suggest otherwise. Isolated cases of cessation of massive haemoptysis from pulmonary aspergillomas in patients considered unfit for surgery when treated with corticosteroids ${ }^{27}$ or with repeated courses of radiotherapy in fractionated doses $^{28}$ have been reported. Remy et $a l^{29}$ recently presented 104 patients with either massive or repeated haemoptysis who benefited from embolisation of the bronchial arteries with resorbable material (Spongel). Cavernoscopic evacuation of aspergillomas followed by repeated instillation into the cavity of antifungal agents (brilliant green, natamycin, gentian violet, or noxithiolin) has been used successfully in high risk patients who have seri- 
ous recurrent haemoptysis. ${ }^{530}$

In view of the suddenness with which haemoptysis may occur in patients who have superimposed aspergillomas in tuberculous cavities, we support the conclusions of earlier reports ${ }^{11} 1522$ that recommend "prophylactic" resection of asymptomatic pulmonary aspergillomas. Of our two patients who had fatal haemoptysis, one had refused surgery in conjunction with the antituberculosis drug treatment despite repeated episodes of haemoptysis and the other had bilateral multiple aspergillomas and died before her staged resection could be completed.

Pulmonary resection for aspergilloma is rarely followed by complications attributable to the $A$ fumigatus provided that lobar resection is performed to prevent the pleural dissemination that frequently occurs with segmental resection. The complication rate in cases with a well localised mycetoma is extremely low. Most of the surgical complications occur in debilitated, anaemic, and elderly patients. The surgical complications of wound infection and empyema thoracis which occurred in our series were in patients debilitated by their disease and age (table 1). These were managed by the administration of appropriate antibiotics and tidal irrigation of the infected pleural cavity with normal saline and antibiotics. ${ }^{31}$ The overall mortality rate in the collected series,,$^{35121520}$ including the 14 cases reported by Kilman et al in $1969,{ }^{11}$ was less than $7 \%$. The only postoperative death recorded in our 10 patients who had surgery was that of a patient with multiple bilateral aspergillomas who had fatal haemoptysis before completion of staged resection; that gave us an operative mortality of $10 \%$. Parker $e a^{l^{32}}$ and Varkey and Rose ${ }^{3}$ recorded a low mortality rate from massive haemoptysis in pulmonary aspergilloma in association with nontuberculous disease. In contrast, Karas et $a^{20}$ and Solit et $a^{15}$ recorded a $25-100 \%$ rate for death from massive haemoptysis in patients who had tuberculosis and coexisting pulmonary aspergillomas.

In conclusion, aspergilloma represents the most common infectious complication of residual pulmonary tuberculous cavities. The most frequent presentation is haemoptysis, which may recur with increasing severity and cause death. We advocate combined preoperative and postoperative antituberculosis drug treatment with surgical resection as a means of forestalling exsanguinating haemorrhage in patients whose clinical condition and pulmonary state do not prohibit operation.

\section{References}

' Campbell MJ, Clayton YM. Bronchopulmonary aspergillosis: correlation of the clinical and laboratory findings in 272 patients investigated for bronchopulmonary aspergillosis. Am Rev Respir Dis 1964;89:186-96.

${ }^{2}$ Strutz GM, Rossi NP, Ehrenhaft JL. Pulmonary aspergillosis. J Thorac Cardiovasc Surg 1972;64:963-8.

${ }^{3}$ Varkey B, Rose HD. Pulmonary aspergilloma. A rational approach to treatment. $A m J \mathrm{Med}$ 1976;61:626-31.

4 Israel HL, Ostrow A. Sarcoidosis and aspergilloma. Am J Med 1969;47:243-50.

5 Jewkes J, Kay PH, Paneth M, Citron KM. Pulmonary aspergilloma: analysis of prognosis in relation to haemoptysis and survey of treatment. Thorax 1983;38:572-8.

- Irwin A. Radiology of the aspergilloma. Clin Radiol 1967;18:432-8.

7 Zimmerman RA, Miller WT. Pulmonary aspergillosis. Am J Roent Rad Ther Nucl Med 1970;109:505-15.

${ }^{8}$ Benjamin JJ, Koerner SK, Grunwald RP, Fell SC. Bilateral pulmonary resections for aspergillomas. Chest 1971;60:107-9.

${ }^{9}$ Belcher JR, Plummer NS. Surgery in bronchopulmonary aspergillosis. Br J Dis Chest 1960;54:35-41.

${ }^{10}$ Bruce R. Case of pulmonary aspergillosis. Tubercle 1957;38:203-8.

"Kilman JW, Ahn CC, Andrews NC. Surgery for pulmonary aspergillosis. J Thorac Cardiovasc Surg 1969;57:642-7.

12 Faulkner SL, Vernon R, Brown PP, Fisher RD, Bender HW Jr. Haemoptysis and pulmonary aspergilloma. Operative versus non-operative treatment. Ann Thorac Surg 1978;25:389-92.

${ }^{13}$ MacPherson P. Pulmonary aspergillosis in Argyll. $\mathrm{Br} J$ Dis Chest 1965;59:148-53.

14 Percora DV, Toll MW. Pulmonary resection for localised aspergillosis. $N$ Engl J Med 1970;263:785-7.

is Solit RW, McKeown JJ Jr., Smullens S, Fraimon W. The surgical implications of intracavitary mycetomas (fungus ball). J Thorac Cardiovasc Surg 1971;62:411-22.

16 Villar TG, Pimentel JC, Freitas E, Costa MF. The tumor-like forms of aspergillosis of the lung: pulmonary aspergilloma. Thorax 1962;17:22-38.

${ }^{17}$ English MD, Henderson AH. Significance and interpretation of laboratory test in pulmonary aspergillosis. $J$ Clin Pathol 1967;20:832-4.

${ }^{18}$ Cohen R, Rott FJ, Delgado E, Ahearn DG, Kalser MH. Fungal floral of the normal human small and large intestine. $N$ Engl J Med 1969;280:638-41.

${ }^{19}$ Mills SA, Wolfe GW. Opportunistic infections of the lung. Surg Clin N Am 1980;60:913-30.

${ }^{20}$ Karas A, Hankins JR, Attar S, Miller JE, McLaughlin JS. Pulmonary aspergillosis: an analysis of thirty-eight cases. Ann Thorac Surg 1976;22:1-7.

${ }^{21}$ Philal V, Jedklickova Z, Vicklicky J, Jomanek A. Multiple pulmonary aspergillomata. Thorax 1964;19:10411.

22 Takaro T. Mycotic infections of interest to thoracic surgeons. Ann Thorac Surg 1967;3:71-7.

${ }^{23}$ Henderson AH, Pearson JEG. Treatment of bronchopulmonary aspergillosis with observation on Natamycin. Thorax 1968;23:519-22.

24 Bindschadler DD, Bennet JE. A pharmacologic guide to the clinical use of amphotericin B. Br J Infect Dis 1969; 120:427-37.

${ }^{25}$ Ramirez J. Pulmonary aspergilloma: endobronchial treatment. N Engl J Med 1964;271:1281-5. 
${ }^{26}$ Krakowka P, Traczyk K, Walczak J, Halweg H, Elsner Z, Pawlicka L. Local treatment of aspergilloma of the lung with a paste containing nystatin or amphotericin B. Tubercle 1970;51:227-45.

${ }^{27}$ Davies D, Somner AR. Pulmonary aspergillomas treated with corticosteroids. Thorax 1972;27:156-62.

${ }^{28}$ Shneerson JM, Emerson PA, Phillips RH. Radiotherapy for massive haemoptysis from an aspergilloma. Thorax 1980;35:953-4.

${ }^{29}$ Remy J, Arnaud A, Fardou H, Giraud R, Voisin C. Treatment of haemoptysis by embolisation of bron- chial arteries. Radiology 1977;122:33-7.

${ }^{30}$ Subba Rao R, Curzon PGD, Muers MF, Watson DA. Cavernoscopic evacuation of aspergilloma: an alternative method of palliation in high risk patients. Thorax 1984;39:394-6.

${ }^{31}$ Deiter RA Jr., Piffarre R, Neville WE, Magno M, Jasuya M. Empyema treated with neomycin irrigation and closed chest drainage. J Thorac Cardiovasc Surg 1969;59:496-500.

${ }^{32}$ Parker JD, Sarosi GA, Doto IL, Tosh FE. Pulmonary aspergillosis in Sanatoriums in the South Central United States. Am Rev Respir Dis 1970;101:551-7. 